\title{
A REPRESENTAÇÃO DOS GEOSSISTEMAS COM ÊNFASE NO ESTUDO DOS RECURSOS HÍDRICOS NA BACIA HIDROGRÁFICA DO RIO CACHOEIRA, BRASIL
}

\author{
Kaique Brito Silva \\ Universidade Estadual de Campinas - UNICAMP, Instituto de Geociências, Campinas, SP, Brasil \\ kbritofb96@hotmail.com \\ Raul Reis Amorim \\ Universidade Estadual de Campinas - UNICAMP, Instituto de Geociências, Campinas, SP, Brasil \\ raulreis@ige.unicamp.br \\ Neylor Alves Calasans Rego \\ Universidade Estadual de Santa Cruz - UESC, Laboratório de Climatologia, Ilhéus, BA, Brasil \\ neylor@uesc.br
}

\begin{abstract}
RESUMO
Estudos de Geografia Física demandam uma leitura de ambientes que conceba os atributos naturais e antrópicos como forças motrizes de sistemas que alteram, ao longo do tempo, fluxo de energia e matéria no espaço geográfico. Essa é a questão central ao qual se aplica a Teoria Geral dos Sistemas, que define os geossistemas como categoria de análise de estudos da paisagem. Considerando tal método, o objetivo central dessa pesquisa foi representar os geossistemas da bacia hidrográfica do rio Cachoeira, Nordeste do Brasil, utilizando-os como recortes para compreensão da hidrografia da área de estudo. Foram definidos 8 geossistemas que apontam interações específicas das unidades do meio físico da paisagem. As informações desses geossistemas contribuem de forma analística para a compreensão de cenários hidrológicos e produção de água numa bacia de importância socioeconomica regional.
\end{abstract}

Palavras-chave: Sul da Bahia. Sistemas naturais. Estudo aplicado.

\section{GEOSYSTEMS REPRESENTATION WITH EMPHASIS IN WATER RESOURCES STUDIES IN THE HYDROGRAPHIC BASIN OF CACHOEIRA RIVER, BRAZIL}

\begin{abstract}
Studies of Physical Geography require a reading of environments involving the natural and anthropic attributes as driving forces of systems that change, over time, the flow of energy and matter in the geographic space. This is the central question to which the General Systems Theory applies, which defines geosystems as the category of analysis of landscape studies. Considering this method, the central objective of this research was to delimit the geosystems of the basin of the Cachoeira river, Northeast of Brazil, using them as cuttings to understand the hydrography of the study area. Eight geosystems have been defined that indicate specific interactions of the units of the physical environment of the landscape. The information from these geosystems contributes to analytically to the understanding of hydrological scenarios and water production in a hydrographic basin of regional socioeconomic importance.
\end{abstract}

Key Words: Southern Bahia. Natural systems. Applied research. 


\section{INTRODUÇÃO}

A Teoria Geral dos Sistemas e suas derivações aplicadas nas ciências da terra têm sido arcabouço teórico-metodológico em diversas pesquisas que questionam e discutem os tipos de processos socioambientais e os atributos do meio físico que influenciam na dinâmica temporal do espaço geográfico. A adoção das Unidades da Paisagem, parte fundamental para explicar um geossistema, é resultante da interação entre sistemas naturais e antrópicos, e incorpora a compreensão de que os territórios em geral estão intimamente ligados as características de evolução no uso dos recursos naturais (CAVALCANTI, 2013; BASTIAN, GRUNEWALD e KHOROSHEV, 2015; BANDEIRA e OLIVEIRA, 2016; GUEDES e DINIZ, 2016).

Inicialmente, os geossistemas são visualizados como porções do espaço geográfico que são individualizadas pela interação dos componentes físico-naturais: relevo, clima, cobertura vegetal, solos e fáceis litológicas formam, em determinado tempo e espaço, um sistema específico no sentido de deslocamento de energia, sedimentos e nutrientes independente da escala de observação. $O$ clímax dessa interação são as fitofisionomias dos domínios vegetais. (GAGARINOVA, 2010; BURKHARD, DE GROOT e COSTANZA, 2012; AMORIM 2016; AMORIM, REIS e FERREIRA, 2017). Dois fatores são essenciais na representação dos geossistemas: as dimensões espaciais e temporais. Os componentes naturais ocupam um determinado espaço e, conforme a abordagem sistêmica, sofrem transformações em um certo período de tempo. Representar os limites dos geossistemas é algo complexo, pois a delimitação de suas fronteiras está ligada a adoção do nível taxionômico adotado (BERTRAND, 1971). Para Amorim e Oliveira (2008), a representação das Unidades da Paisagem é complexa, pois a interação entre os diversos atributos dos geossistemas e sistemas antrópicos permitem a identificação dos atributos responsáveis pela dinâmica das paisagens, assim como apontar as principais fragilidades ambientais de cada unidade, elemento essencial na gestão do território.

A definição mais holística que (des)agrega o fixos "geo" e "sistema" e traz uma definição mais ampla, que é exposta por Amorim e Oliveira (2013), derivada de Sochava (1977): [1] um geossistema é sinônimo de formações naturais subordinados a dinâmica dos fluxos de matéria e energia, buscando equilíbrio no que tange a eventuais alterações em seus elementos do sistema natural; [2] As ações antrópicas interferem na funcionalidade, estrutura e organização desses sistemas, que são abertos, que desencadeia numa mudança de entropia dos mesmos.

A paisagem é o plano de fundo para identificar esses sistemas naturais e antrópicos. Os resultados de uma leitura geossistêmica sempre perpassarão na construção de representações espaciais, que são o produto tangível dessa metodologia: além de obter habilidades para estruturar as unidades da paisagem (natural ou antrópica), o pesquisador deve atentar-se às escalas de estudo. Categoricamente, Vinogradov, Gerenchuk e Isachenko (1962) compartimentam quatro (4) escalas de estudos geossistêmicos, atribuídos aos elementos do Geossistema: [1] fáceis e [2] tratos, nuances retratados em trabalhos de escala de detalhe até seus conjuntos em escala 1:100.000; [3] localidades, associações ou complexos de tratos representados em escala média, no intervalo entre 1:100.000 até 1:1.000.000; [4] Paisagens, que são grandes sistemas expostos acima da escala de complexo de tratos.

Nesse sentindo, a gama conceitual abordada apresenta-se como ideal para estudos em recorte geográficos de quaisquer dimensões espaciais com o intuito de entender o estado natural do ambiente e as direções de fluxos de energia e matéria, a exemplo de grandes, médias e pequenas bacias hidrográficas. De forma icônica, entender os caminhos que os cursos d'água fazem sobrepostos a diversos substratos geológicos, pedológicos, adjacentes a domínios de fauna e flora e condicionados a variáveis climáticas, pode se classificado como chave nos estudos aplicados aos geossistemas e serviços ecossitêmicos (SOARES e AQUINO 2012; MUBAREKA, 2013).

No caso de bacias hidrográficas de importância regional, o entendimento da dinâmica das águas percorrendo os diferentes geossistemas permite um agregar de informações sobre a hidrologia (qualidade e quantidade da água), usos prioritários e gerenciamento e gestão dos recursos hídricos. É nessa perspectiva que as representações geossistêmicas dos trabalhos de Amorim (2016), Amorim, Reis e Ferreira (2017), Bastian, Grunewald e Syrbe (2012), Bastian, Grunewald e Khoroshev (2015), Burkhard, De Groot e Costanza (2012), Gagarinova e Kovalchuk (2010) e Mubareka (2013) tratam as relações dos sistemas naturais e antrópicos numa abordagem que envolve produção da água (municipal e estadual), uso da terra, vulnerabilidade socioambiental e indicadores de serviços ecossistêmicos. A concepção geral dos autores é de que a água assume um papel central nas discussões que envolvem formas de energia e suas relações com as atividades socioeconômicas de determinado recorte geográfico, sendo a bacia hidrográfica delimitada para tal compreensão.

$\begin{array}{llllll}\text { Caminhos de Geografia } & \text { Uberlândia - MG } & \text { v. 19, n. } 67 & \text { Set/2018 } & \text { p. 53-67 } & \text { Página } 55\end{array}$


A partir da representação dos sistemas naturais, o objetivo deste trabalho foi representar e caracterizar os geossistemas da bacia hidrográfica do rio Cachoeira, região nordeste do Brasil, subsidiando uma leitura de ambientes a partir de um viés que relacione água e paisagem. Por se tratar de uma bacia hidrográfica de importância regional e de feições heterogêneas, descrever a paisagem de seus compartimentos hidrográficos permite visualizar os diferentes sistemas naturais que definem a qualidade e quantidade de água. A proposta apresentada é uma abordagem metodológica formulada com o intuito de surgir como um novo mecanismo nos estudos e planos de gestão de bacias hidrográficas, sobretudo em fases de planejamento, zoneamento e diagnóstico ambiental.

\section{PASSO A PASSO METODOLÓGICO}

\section{Área de Estudo}

A bacia hidrográfica do rio Cachoeira localiza-se no sul do estado da Bahia, Nordeste do Brasil. Tem centróide nas coordenadas $15^{\circ} 2^{\prime} \mathrm{S}$ e $39^{\circ} 30^{\prime} \mathrm{W}$ (Figura 1) e drena uma área de 4.222 km². A mesma faz parte da região de gestão de águas do Atlântico Leste conforme a Agência Nacional de Águas - ANA. Esta bacia fornece água para o abastecimento público de cerca de 500.000 habitantes distribuídos nas cidades de Itororó, Itajú do Colônia, Ibicaraí, Floresta Azul, Itapé, Ilhéus e Itabuna, tendo a ultima a maior população, estimada em 220.300 habitantes (IBGE, 2015). De acordo com a classificação internacional de Koppen (1936), prevalece na área os tipos climáticos Af e Aw, classificados como Tropical Úmido de Floresta e Subúmido, respectivamente, e ambos sem estação seca definida. Segundo Thornthwaite (1948), Alvares, Stape e Sentelhas (2013) e Silva et al. (2016), esse clima caracteriza-se também pelas métricas de temperatura média de $24^{\circ} \mathrm{C}$, e precipitação anual acima de $2.000 \mathrm{~mm}$. Ainda segundo o autor, os valores de chuva indicam que essa região é um domínio com níveis pluviométricos similares ao clima Amazônico.

Figura 1: Localização da bacia hidrográfica do rio Cachoeira

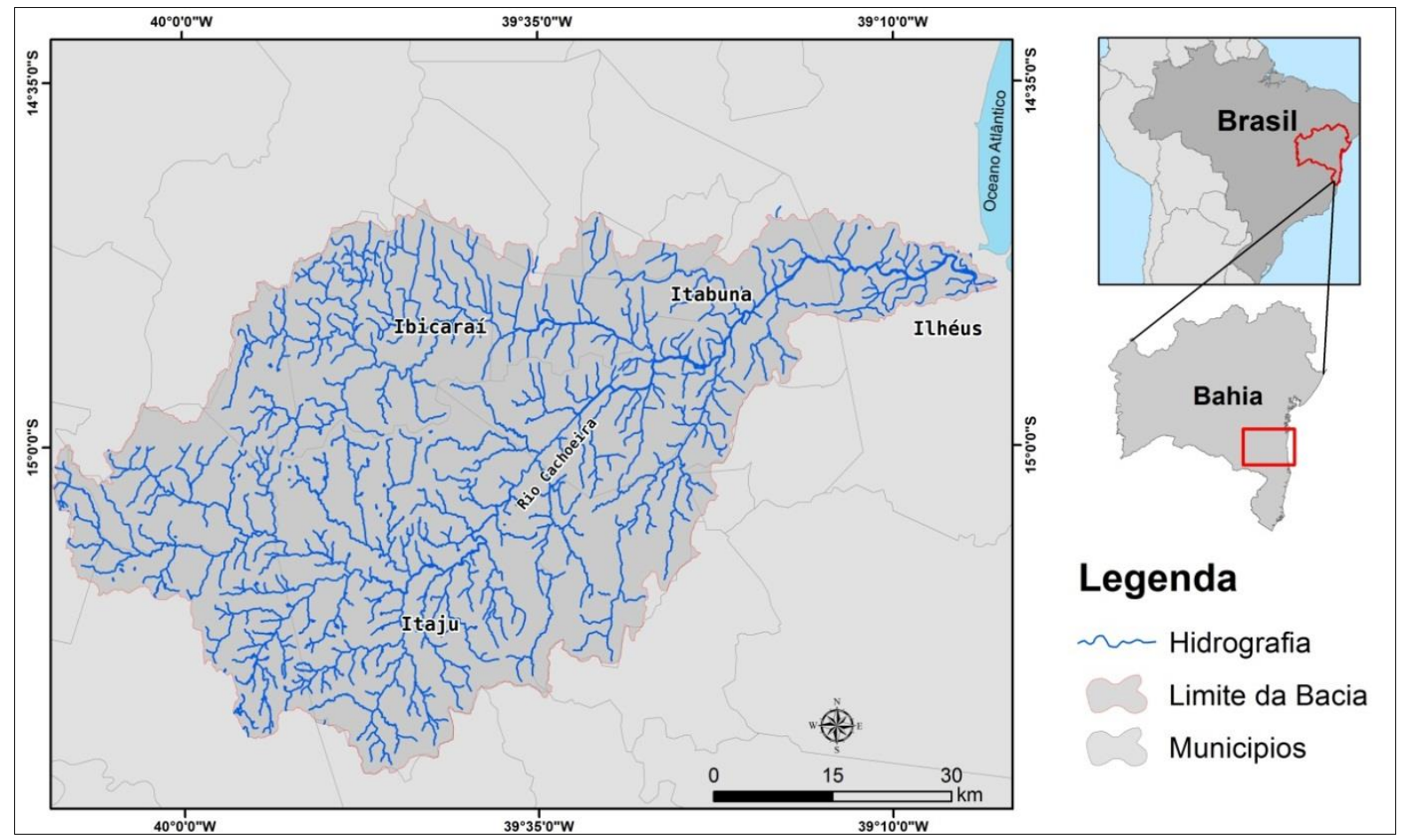

Fonte: Elaboração dos autores a partir da base de dados SEl (2004)

No que concerne aos recursos hídricos da região, Santos, Paula e Rego, (2008) e Franco et al. (2011) afirmam que a densidade de drenagem média da bacia é de $2,35 \mathrm{rios} / \mathrm{km}^{2}$, caracterizando um sistema hidrológico superficial abundante. Já as águas subterrâneas da região, de acordo com Maia, Cruz e Sampaio (2009), ocorrem em domínios de rochas do embasamento cristalino, o que determina aquíferos dos tipos fissurais, de baixo a médio potencial hidrogeológico. O domínio vegetal da região é a Floresta

\begin{tabular}{llllll}
\hline Caminhos de Geografia & Uberlândia - MG & v. 19, n. 67 & Set/2018 & p. 53-67 & Página 56
\end{tabular}


Tropical Úmida (Mata Atlântica), de fitofisionomia ombrófila. Entretanto, devido às alternâncias econômicas da região, desenvolvidas atualmente em atividades agropastoris, o cenário de intenso desmatamento na bacia hidrográfica marca a paisagem local já há alguns anos. A retirada da vegetação, o aumento da vulnerabilidade ambiental e o déficit nos níveis de vazão das sub-bacias são apontamentos observados por Harum et al. (2008), Santos, Paula e Rego (2008), Rego, Barros e Santos (2010) e Franco et al. (2011).

\section{Definição das unidades de paisagem}

Para a representação dos geossistemas nos limites da bacia hidrográfica do rio Cachoeira, alguns padrões de representação (trazidos por Amorim e Oliveira (2013), Amorim (2016) e Amorim, Reis e Ferreira (2017) foram considerados para a análise em escala regional proposta. A extenção territorial de representação configura-se como desprezível, pois a mesma por si não é sinônimo de agrupamento das feições naturais (o mesmo de táxons). Dessa forma, adota-se uma leitura da paisagem determinando a homogeneidade e/ou heterogeneidade dos táxons, que de forma simplicada são os contornos das unidades da paisagem do meio físico, desde a geologia até o tipo climático.

Assim, para visualizar os geossistemas da área em estudo, inicialmente foi adotada uma classificação das unidades de paisagem em geômeros (onde as fáceis caracterizam cenários hemogêneos) e geócoros (uma heterogêneidade de formas "trato" que diferem desde seu desenho até sua dimensão), conforme o esquema da Figura 2 (SOCHAVA,1971; 1975; 1977). Em escala regional, a heterogeneidade é menos presente devido a generalização que a imagem da paisagem expõe, diferente da escala local (GAGARINOVA e KOVALCHUK, 2010; BASTIAN, GRUNEWALD e KHOROSHEV, 2015). A Figura 2 categoriza os geômeros como geossistemas de estrutura homogênea, enquanto os geócoros são geossistemas com estrutura heterogênea.

Figura 2: Esquema metodológico das ordens dos geossistemas.

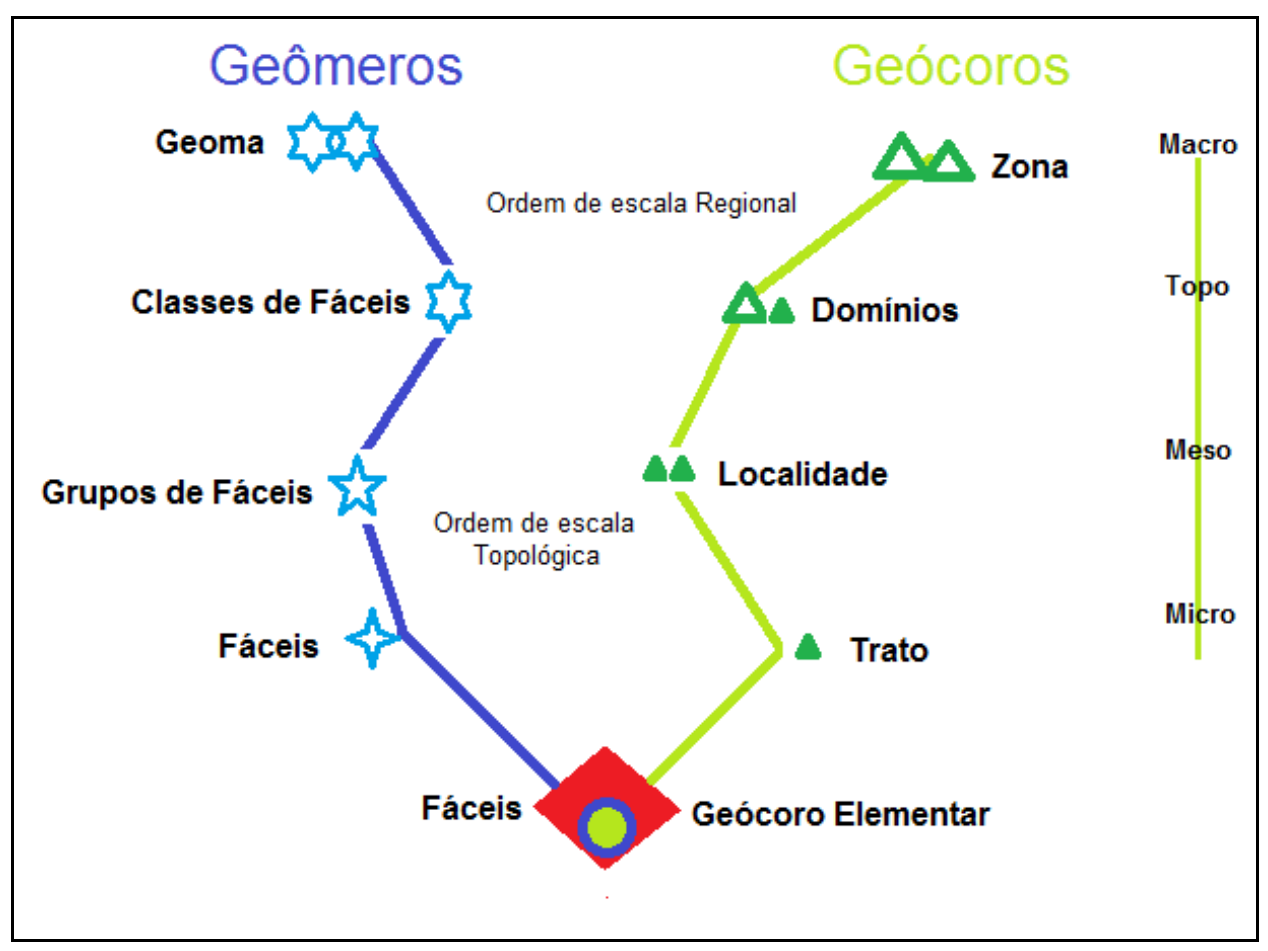

Fonte: Adaptado de Amorim, Reis e Ferreira (2017).

Após o entendimento das posições dos geômeros e geócoros, delineia-se uma compartimentação dos elementos do meio físico em diferentes escalas de análise. Este trabalho adota os procedimentos já testados por Amorim e Oliveira (2008, 2013), Burkhard, Kandziora e Hou (2014), Amorim (2016), Amorim, Reis e Ferreira (2017) em estudos geossistêmicos na Rússia e nos estados brasileiros da Bahia, Rio de Janeiro e São Paulo. Considerando a escala regional da pesquisa e apontamentos observados em

$\begin{array}{llllll}\text { Caminhos de Geografia } & \text { Uberlândia - MG } & \text { v. 19, n. } 67 & \text { Set/2018 } & \text { p. 53-67 } & \text { Página } 57\end{array}$


Isachenko (1973) Gagarinova e Kovalchuk (2010), a representação dos geossistemas da área em estudo abarcou informações inerentes:

(1) ao domínio morfoestrutural - Conjunto de rochas que deu origem ao substrato. Considerando que o mapeamento geológico a ser utilizado é de média e pequena escala, identificar com exatidão o limite de cada rocha matriz que deu origem ao substrato não se aplica, mas a formação, grupo, província ou complexo geológico, sim, uma vez que os processos atuantes na gênese desse conjunto de rochas apontam muito sobre seu comportamento nos processos intempéricos na paisagem (SOARES e AQUINO, 2012);

(2) às formas de Relevo - Para escala grande, define-se a compartimentação das formas de relevo derivadas de topossequência, tendo como auxílio a construção de unidades gerais de dissecação e deposição. Para a escala regional adota-se os compartimentos do relevo;

(3) às classes de Solos - São as características gerais das formações superficiais, sejam sedimentos, pedimentos, mantos de alteração e perfis pedológicos. Junto com a vegetação, apresenta-se como indicador determinante das características de fluxo de energia, matéria e nutrientes. No presente estudo adotou-se o primeiro táxon da Classificação de Solos elaborada pela Embrapa (2013);

(4) ao tipo Climático - Predomínio de características meteorológicas ao longo do tempo, sobretudo definido pelos índices de pluviosidade, considerando a água como força motriz para os sistemas naturais.

(5) à cobertura Vegetal Natural - O domínio de vetação respectivo ao cenário em análise, não considerando as variações fitofisionômicas percebidas apenas em escala de detalhe.

\section{Geoprocessamento}

A composição dos geossistemas foi desenvolvida através do somatório de representações georreferenciadas em um banco de dados cartográficos com informações inerentes às unidades do meio físico [1] domínios morfoestruturais, [2] relevo, [3] solo, [4] zonas climáticas (segundo Koppen, 1936), [5] bioma. Adotou-se uma escala regional de análise, de métrica 1:250.000, considerando o nível de detalhe em que foram geradas as cinco informações cartográficas utilizadas, integrando camadas dos componentes físico-naturais da paisagem. Além disso, foi adotada a escala gráfica 1:300.000 para a representação do mapa de geossistemas gerado. Todos esses dados são obtidos em arquivos digitais no formato Shapefile (.shp), disponíveis através do sistema cartointerativa da SEI, (2004), IBGE, (2015) e Processamento Digital (2017). Especificamente a carta de solos foi refinada de acordo com os processos pedogenéticos e seus contornos relacionados com a topografia da área, conforme recomenta Amorim (2016), expondo que a classe de solos, após a vegetação, é a que permite delimitar precisamente as nuances geossistêmicos.

Em segundo momento, foi realizado o levantamento das cartas topográficas que abrangem os municípios pertencentes a bacia hidrográfica, onde foram selecionadas seis (6) cartas topográficas na escala 1:100.000 produzidas pela Superintendência de Desenvolvimento do Nordeste: Camacan (SD-24-Y-D-III) (SUDENE, 1977a), Itabuna (SD-24-Y-B-VI) (SUDENE, 1977b), Ibicaraí (SD-24-Y-B-V) (SUDENE, 1977c), Itapetinga (SD-24-Y-D-I) (SUDENE, 1977d), Itaju do Colônia (SD-24-Y-D-II) (SUDENE, 1977e), e Poções (SD-24-Y-B-IV) (SUDENE, 1977f). O intuito do uso dessas cartas foi um refinamento dos polígonos dos geossistemas, bem como os limites da bacia hidrográfica, levando em conta principalmente os contornos das curvas de nível nos arquivos de hipsometria - curvas de nível. A hidrografia da área em estudo foi extraída também da base de dados vetorizada oriunda das cartas topográficas mencionadas.

Toda a conjuntura de dados reunidos foi realizada através de geoprocessamentos no Sistema de Informação Geográfica ArcGIS 10.3: primeiramente, foram importados os dados do meio físico para composição das camadas (layers) e organização das sobreposições. Em seguida, realizou-se uma mesclagem dos arquivos utilizando as tabelas de atributos (comando join table), definindo manualmente em cada célula as siglas dos geossistemas a serem gerados e suas localizações. O uso de siglas nas legendas dos geossistemas é um layout recomendável por Sochava (1977), que explica que a forma adequada de expor as unidades de paisagem é a forma de matriz, em decorrência de eventuais diversidades de sistemas e subsistemas. Essa representação é observada nos trabalhos de Bastian, Grunewald e Khoroshev (2015), Burkhard, De Groot e Costanza (2012) Burkhard, Kandziora e Hou (2014) Amorim, Reis e Ferreira (2013; 2017). Em seguida, na tabela de coordenadas de cada unidade geossistêmica identificada, realizou-se uma adequação para os limites da bacia (comando clip). Por fim, após a composição dos geossistemas no interior da bacia hidrográfica, gerou-se um único arquivo shapefile, contendo as posições geográficas e as informações de legenda das unidades de paisagem em estudo.

\begin{tabular}{llllll}
\hline Caminhos de Geografia & Uberlândia - MG & v. 19, n. 67 & Set/2018 & p. 53-67 & Página 58
\end{tabular}




\section{RESULTADOS E DISCUSSÃO}

De acordo com os dados das unidades do meio físico relacionados, foram identificados oito (8) geossitemas para bacia hidrográfica do rio Cachoeira compostos pelos seguintes atributos e suas respectivas siglas: Geologia - Maciços Cristalinos Pré-Crambrianos $(\mathrm{m})$ e Depósitos Sedimentares Quaternários (c); Relevo - Planície de Acumulação (A), Mares de Morro (M), Serras (S) e Depressões (D); Pedologia - Latossolos (It), Argissolos (ar), Chernossolos (ch) e Gleissolos (sm); Clima - Úmido (U) e Subúmido (SU); Bioma - Mata Atlântica.

Totalizando treze (13) atributos associados, é possível encontrá-los descritos também em trabalhos com foco em análises ambientais na bacia hidrográfica, sobretudo voltados para recursos hídricos, como os de Rego, Santos e Teixeira (2010) Santos, Paula e Rego (2008) e Lucio, Santos e Silva (2010) que relacionaram aspectos de qualidade e quantidade da água com os atributos geológicos e pedológicos, e Harum et al. (2008), Paula, Silva e Souza (2012) e Chaussê et al. (2016) que descrevem as influências dos sistemas naturais e antrópicos em aspectos que envolvem a produção de água numa avaliação espaço-temporal, além da caracterização da morfometria superficial e subsuperficial e suas feições geológicas em canais de drenagem da bacia hidrográfica do rio Cachoeira. As associações geossistêmicas estão expostas na matriz da Tabela 1 e representados na Figura 3:

Tabela 1: Matriz dos gessositemas para a bacia hidrográfica do rio Cachoeira.

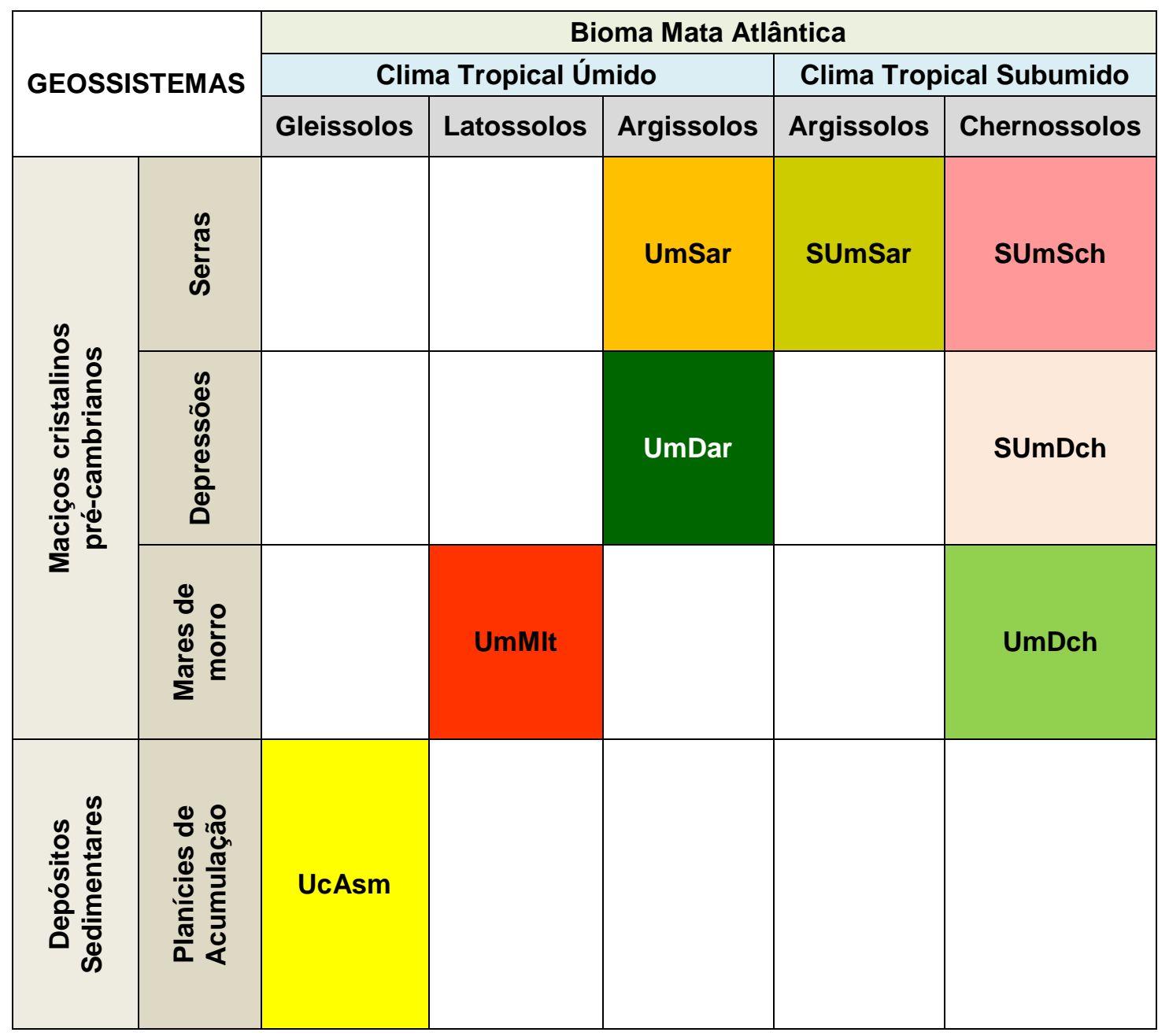

Fonte: Elaboração dos autores através de dados de pesquisa. 
Figura 3: Geossistemas da bacia hidrográfica do rio Cachoeira.

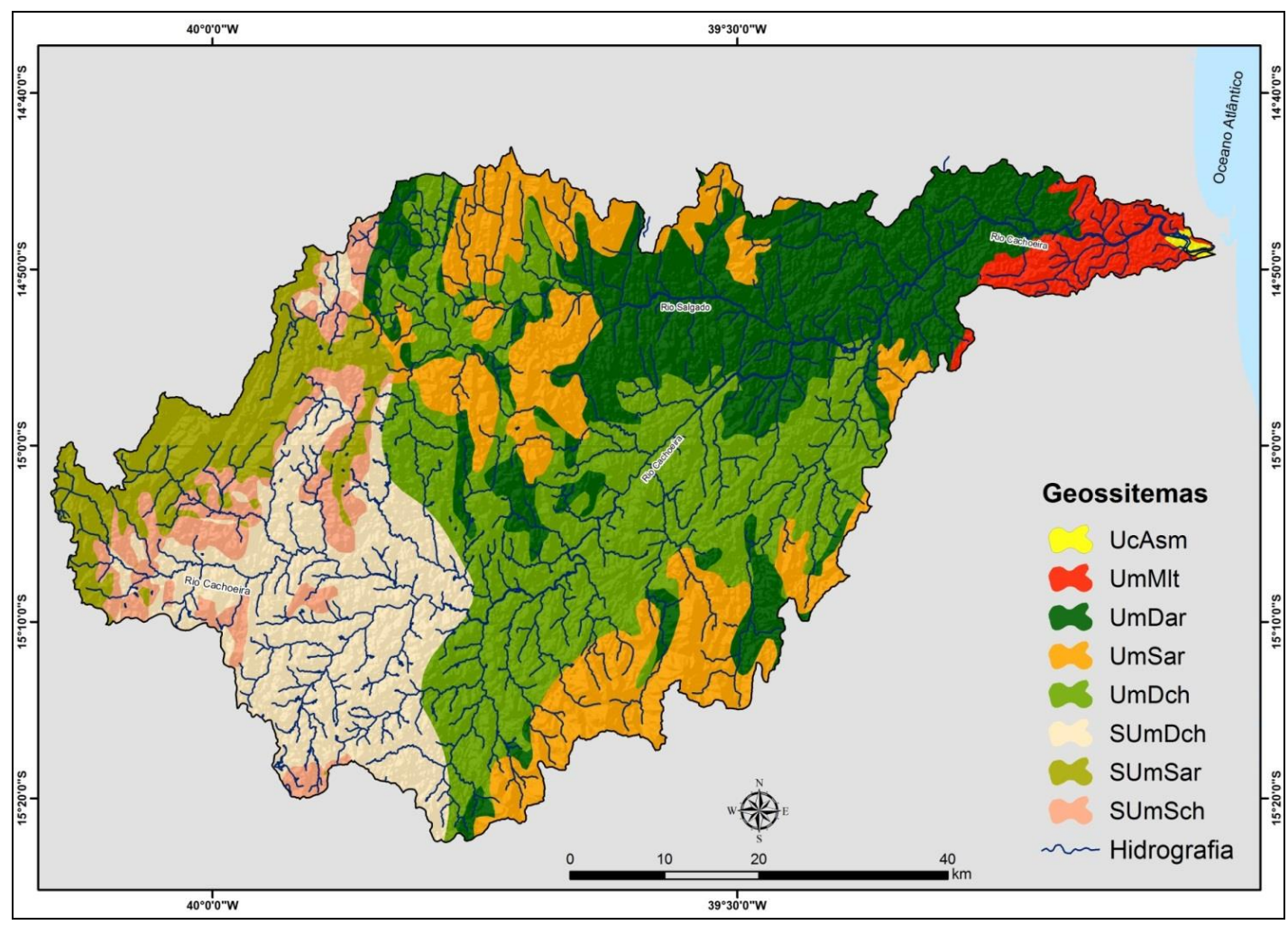

Fonte: Dados gerados pela pesquisa (2017).

Com exceção do geossitema "UcAsm", os rios da bacia hidrográfica em estudo drenam uma geologia constituída predominantemente de rochas ígneas intrusivas, da família do Ortognaisse, que formam o atributo geossistêmico de Maciços Cristalinos Pré-Crambianos. Para a área em estudo, são rochas associadas ao período Arqueano, especificamente a era do Proterozóico Superior (4,5 M.a A.P). Compõem basicamente dois grandes grupos: o cinturão Itabunalltapetinga e o Complexo lbicuí, que afloram como ocorrências de Tonalitos, Charnockitos, Sienitos, Quartizitos e Basaltos (EVANS, HEAMAN e TRINDADE, 2010; PEDREIRA, 1997; PEDREIRA e WAELE, 2008; GUADAGNIN et al. ,2015; MAGALHAES et al., 2015). Esse litotipo condiciona uma hidrologia fissural, com falhas geológicas lineares, moldando em aproximadamente $78 \%$ hidrografia para o tipo Dentrítica.

Nos geossistemas "UmDch" e "UmDar", ambos inseridos no compartimento de relevo classificado como Depressão, a predominância de Sienitos e Basaltos trazem consigo, em seus afloramentos nos leitos dos canais de drenagem, um litotipo fitado com faixas de quartzo, biotitas e anfibólios. Segundo Paula, Silva e Souza (2012) e Silva (2016), o processo de dissolução dos minerais citados são responsáveis pelos elevados índices de salinidade (altas concentrações $\mathrm{Na}^{+}$) das águas superficiais, sendo inclusive atribuída a essa porção do médio curso o nome de "rios salgados" (Figura 4).

Os principais locais que produzem as águas que chegam até os geossistemas supracitados estão inseridos nas serras que compõem o geossistema "UmSar", frisando que esse recorte está submetido ao clima úmido da região. Além de tais atributos, nessas áreas elevadas predominam também os Argissolos, a cobertura vegetal de Mata Atlântica remanescente, que permite uma produção de água maior quando comparada a outras porções da bacia hidrográfica em que predominam sistemas agropecuários, conforme Souza et al. (2009). São nessas áreas que, segundo Santos, Paula e Rego (2008) e Silva (2016), a produção de água gira entorno de $0,05 \mathrm{~m}^{3} / \mathrm{s}$ nos afluentes do rio Cachoeira. 
Figura 4: A) depósitos de sal no leito do rio Cachoeira; B) Vista das serras que compõem os geossistemas "SumSar" e "UmSar".

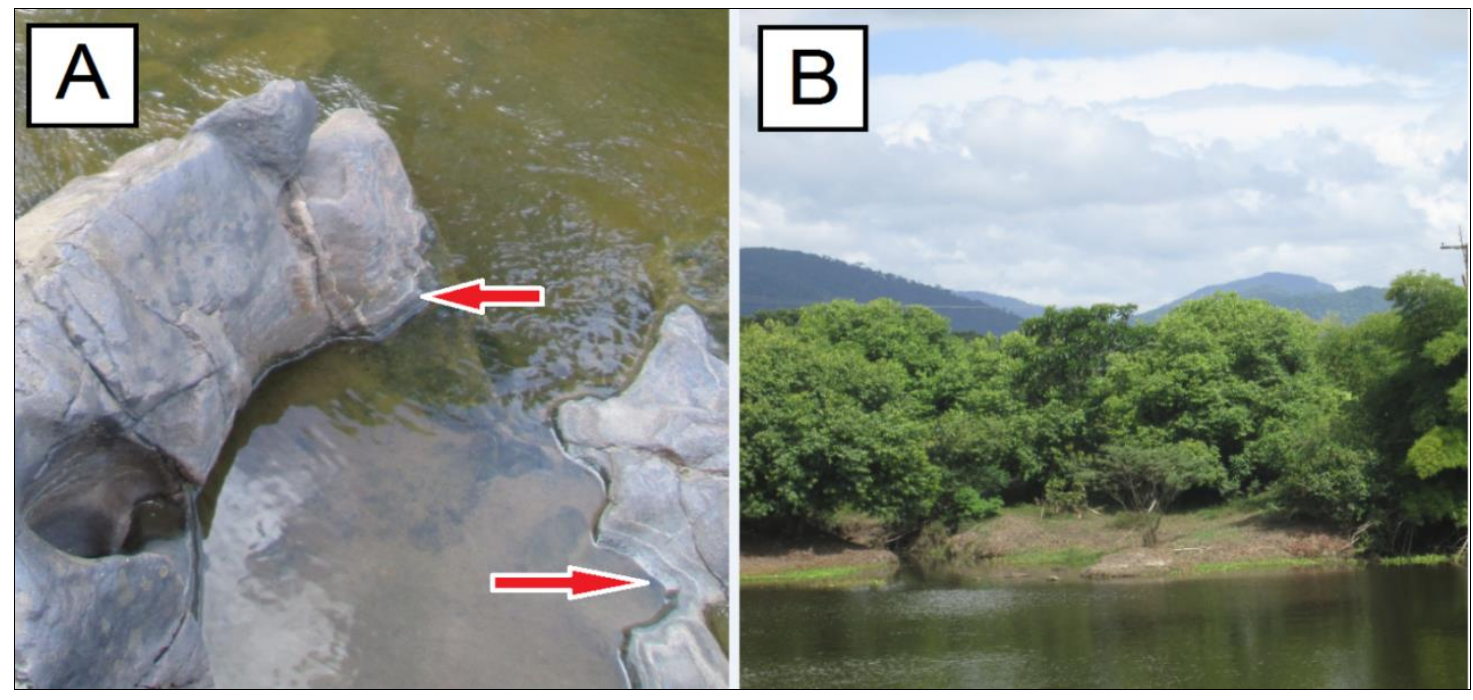

Fonte: Dados de pesquisa (2017).

O Argissolo é um atributo presente também no geossistema "SUmSar", caracterizado pelo de compartimento geomorfológico de serras: a posição desse geossitema no alto curso da bacia hidrográfica congrega as princiais áreas de nascentes das duas maiores sub-bacias da área, a do rio Colônia (drenagem oeste>leste) e Salgado (drenagem norte>leste). Dada a ocorrência de Argissolos nas áreas elevadas da bacia, Campos et al. (2012) expõe que essa formação pedológica propicia menores níveis de infiltração quando comparado com Latossolos e Chernossolos, por exemplo. Segundo Silva et al. (2011), o que favoreceria a presença de nascentes perenes seria o resultado da [1] textura de uma relação $1 / 2$ de partículas tamanho areia em mistura com argila, [2] topografia movimentada e [3] baixa permeabilidade oriunda também dos gnaisses constituídos de quartzo. Esse cenário de produção de água é atingindo atualmente pelo uso da terra pautado em atividades agropecuárias (SOUZA et al. 2010; SILVA et al., 2011; SILVA, 2016).

Os geossistemas que completam o alto curso da bacia hidrográfica são "SUmSch" e "SUmDch", destacados pela ocorrência dos Chernossolos. De forma geral, na área em estudo, apresentam-se como solos escuros de alta atividade de argila ( $\mathrm{Ta}$ ) e alta saturação por bases (alto V\%). Ao longo das propriedades rurais, a feição do solo é marcada por slickensides. Segundo Santos, Paula e Rego (2008), Silva et al. (2011) e Melfi (2012), sua ocorência está associada às rochas que possuem minerais que permitem a formação de solo com alto teor de cátions de reação alcalina (principalmente $\mathrm{Ca}^{+}$e $\mathrm{Mg}^{+}$), como os anfibólios presentes no Tonalito. É recorrente a presença de caulinita nesses perfis pedológicos. Em trabalhos que foram realizadas coletas de amostras de água em campo, como os de Figueiredo e Rego (2008) e Silva (2016), é apontado que os canais de drenagem dessa área ao longo do ano, sobretudo o do rio Cachoeira, apresentam elevados níveis de Cálcio. Nessa área, inclusive, há captação de água bruta da cidade de Itajú do Colônia, que segundo Silva (2016), tem seu sistema de tratamento de água com maiores custos em função da correção da carga alcalina para a distribuição.

Os cenários do meio físico do baixo curso da bacia hidrográfica são completados pelos domínios dos geossistemas "UmMlt" e "UsAsm". Essa é porção da bacia que detém os maiores níveis de precipitação ao longo do ano, cujas isolinhas definem os valores entre 2.220 e $2.300 \mathrm{~mm}$, com os canais de drenagem apresentando valores de vazão acima de $10 \mathrm{~m}^{3} / \mathrm{s}$. Nessa zona, o rio Cachoeira já apresenta um leito maior com largura média de 55 metros, até seu exutório. No geossistema "UmMlt", existe a predominância dos Latossolos, que, de forma geral, são solos com baixos níveis de nutrientes e com perfis profundos, retratatos como solos "antigos e lavados", sendo o uso da terra nessa área totalmente baseado no cultivo de cacau em consórcio com a floresta, e intercalado com áreas de remanescentes florestais. Esse atributo pedológico é citado em trabalhos que determinaram o aporte de ácidos orgânicos dissolvidos e nutrientes das águas superficiais, como o de Freitas et al. (2015), Silva et al. (2016), Araújo et al. (2015) e Costa et al. (2017). Estas pesquisas indicam que há

$\begin{array}{llllll}\text { Caminhos de Geografia } & \text { Uberlândia - MG } & \text { v. 19, n. 67 } & \text { Set/2018 } & \text { p. 53-67 } & \text { Página } 61\end{array}$


nesse sistema natural uma deposição contínua de matéria orgânica nos solos e eventualmente nos corpos d'água. É comum, em meses mais secos, que os rios apresentem desenvolvimento de macrófitas. Os autores categoriamente afirmam também que a cadeia de nitrogênio é um indicador de que as águas da bacia hidrográfica do rio Cachoeira são heterogêneas, e que compostos químicos, como nitrito $\left(\mathrm{NO}_{2}\right)$ e nitrato $\left(\mathrm{NO}_{3}\right)$, são resultantes das diferentes interações entre o meio físico e o uso da terra (geossistemas). Além disso, para o geossistema de ambiente estuarino "USmAs", as variáveis inorgânicas Cloro $\left(\mathrm{Cl}^{+}\right)$e Fosfato $\left(\mathrm{PO}_{4}\right)$, presentes nas águas salinas de interação continente-oceano, indicam uma forte influência de águas residuais provinientes dos outros compartimentos à montante da bacia hidrográfica.

De forma geral, os níveis de precipitação do clima tropical de floresta, que predomina na bacia hidrográfica, favorecem a lixiviação contínua dos atributos do meio físico dos geossistemas em estudo, confirmados por similaridades na densidade de drenagem (Tabela 2). Mesmo com a diferenciação entre zonas úmidas (médio e baixo curso) e subúmidas (alto curso), é possível visualizar contínuos valores de vazão ao longo do ano nos canais de drenagem da bacia, sobretudo nas serras. A exceção é recorrente em períodos de estiagem severa em decorrência do El Niño, sendo também atribuída à ausência de vegetação em áreas do compartimento de Depressão, e incorrendo no interrompimento de fluxos de água, como nos anos de 1997 e 2015, em que as cidades da bacia hidrográfica sofreram redução na distribuição.

Tabela 2: Síntese das características das águas nos geossistemas.

\begin{tabular}{|c|c|c|c|}
\hline Geossistema & Curso da bacia & $\begin{array}{c}\text { Densidade de } \\
\text { Drenagem } \\
\left(\mathbf{k m} / \mathbf{k m}^{2}\right)\end{array}$ & Principais Características \\
\hline UmSar & Médio & 0,35 & Canais com vazão acima de $50 \mathrm{l} / \mathrm{s}$ \\
\hline UmDar & Médio & 0,38 & $\begin{array}{c}\text { Águas com elevados níveis de } \mathrm{Na}^{+} \\
\mathrm{e} \mathrm{K}^{+}\end{array}$ \\
\hline UmDch & Médio & 0,41 & Águas com elevados níveis de $\mathrm{Na}^{+}$ \\
\hline UmMlt & Baixo & 0,3 & $\begin{array}{c}\text { Águas com elevada presença de } \\
\text { matéria orgânica }\end{array}$ \\
\hline SumSar & Alto & 0,29 & $\begin{array}{l}\text { Predominância de canais de } 1^{\text {a }} \\
\text { ordem }\end{array}$ \\
\hline SumSch & Alto & 0,33 & Águas ricas em $\mathrm{Ca}^{+}$ \\
\hline SumDch & Alto & 0,39 & $\begin{array}{l}\text { Deposição de sal no leito e bordas } \\
\text { dos canais de drenagem }\end{array}$ \\
\hline UcAsm & Baixo & 0,2 & Manguezal, ambiente estuarino \\
\hline
\end{tabular}

Fonte: Dados gerados pela pesquisa (2017).

Conforme a Figura 5, que expõe o perfil longitudinal do rio principal (Cachoeira), a forma alongada da bacia hidrográfica, atrelada às estruturas de relevo depressional da paisagem, conforma uma drenagem de maior extensão no Geossistemas "SUmDch", "UmDch" e "UmDar" em aproximadamente $160 \mathrm{~km}$. O rio em seu alto curso não drena mais que $15 \mathrm{~km}$ nos geossistemas situados no compartimento serrano. 
Figura 5: Perfil longitudinal do rio Cachoeira

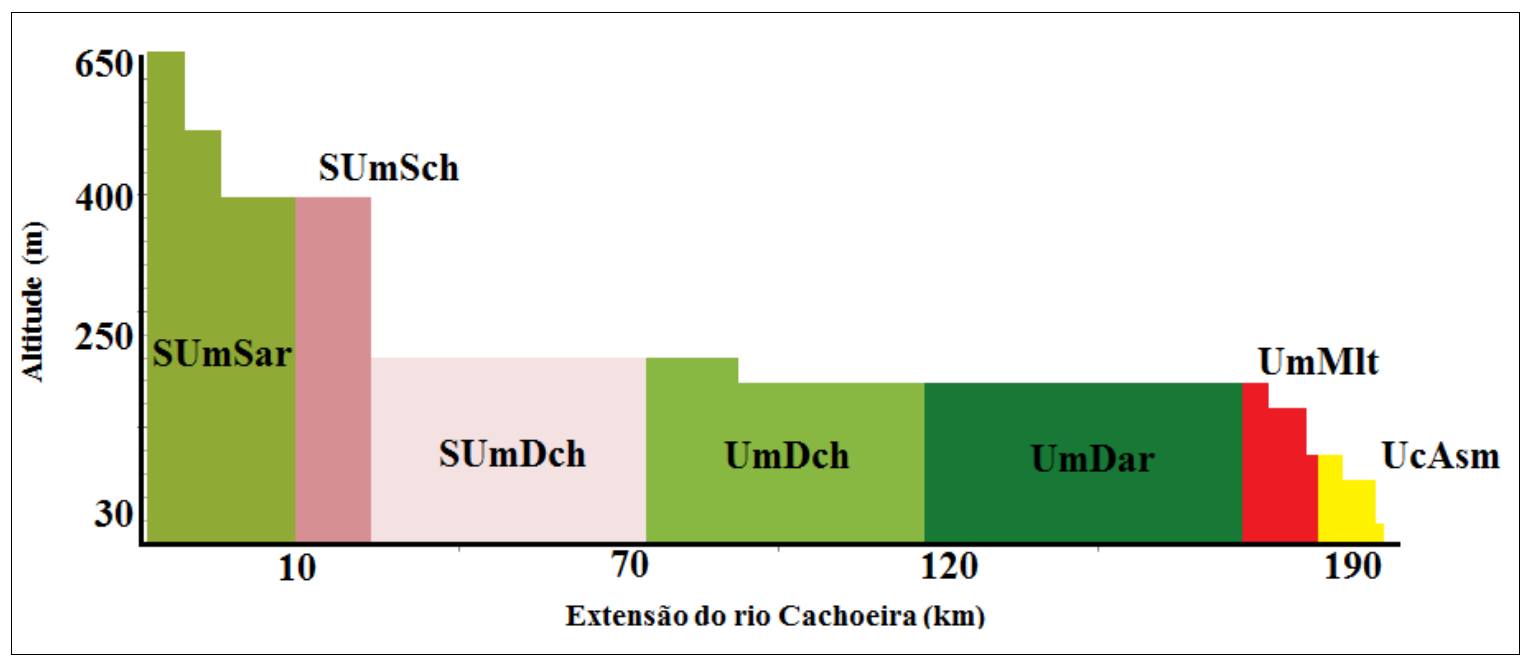

Fonte: Dados gerados pela pesquisa (2017).

Já no baixo curso, o trecho com maior sinuosidade do rio principal está na drenagem do geossistema "UcSam", onde as rochas do embasamento cristalino, ao longo do leito do rio, não afloram e são recobertas por sedimentos quaternários. Até o seu exutório, este é o único trecho navegável em toda a sua extensão, e as características das águas nessa área, segundo Chaussê et al. (2016), é de elevada concentração de matéria orgânica, bem como elevada salinidade oriunda de processos de intrusão salina a partir do mar (Figura 6).

Figura 6: A) Sinuosidade do rio Cachoeira no geossitema "UcSam"; B) Paisagem de manguezais no ambiente estuarino.

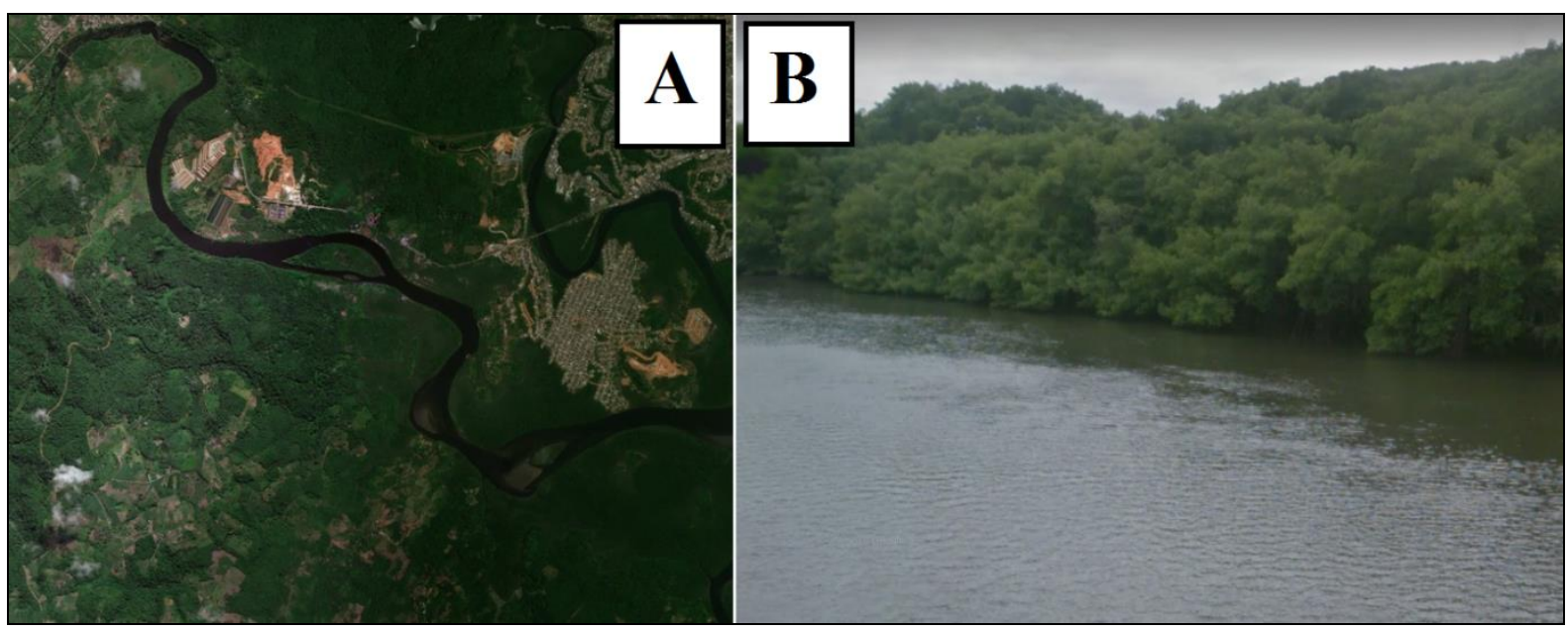

Fonte: Dados de pesquisa (2017).

\section{CONCLUSÕES}

Numa perspectiva de produção de água, os geossistemas "UmSar" e "SumSar" são fundamentais para manutenção dos níveis de vazão positivos ao longo do ano na bacia hidrográfica. Planos de recuperação de nascentes e efetivação de áreas de proteção permanentes podem visualizar, por exemplo, que além dos geossistemas supracitados, a manutenção do curso d'água deve auxiliar uma \begin{tabular}{llllll}
\hline Caminhos de Geografia & Uberlândia - MG & v. 19, n. 67 & Set/2018 & p. 53-67 & Página 63
\end{tabular} 
menor concentração de componentes orgânicos e inorgânicos, como o sódio e matéria orgânica, ao longo dos rios nos geossistemas "SUmDch", "UmDch", "UmDar" e "UmMlt". São nessas áreas que se encontram boa parte dos pontos de captação de água bruta de cidades e distritos ao longo da bacia hidrográfica, bem como os sistemas de tratamento e distribuição de água. As informações hidrológicas discutidas ao longo dos resultados fazem parte de um levantamento bibliográfico que expõe os cenários hidrológicos da bacia. Para cada geossistema, observou-se que são dados congruentes e condizentes com o cenário natural da região, efetivando assim a capacidade de um diagnósitico de recursos hídricos através da abordagem sistêmica.

Ao longo dos cursos da bacia hidrográfica, as associações dos atributos do meio físico e suas relações com informações sobre a qualidade e quantidade de água demonstram que um estudo geossistêmico é eficaz no sentido de visualizar a influência dos sistemas naturais nos recursos hídricos de uma região, evidenciando a disponibilidade da água para determinados usos. Em alusão aos trabalhos de zoneamento que são comuns na ciência geográfica atual, delimitar fáceis de dinâmica entre os sistemas naturais, visualizando principalmente as heterogeneidades, se apresentam como uma alternativa para o planejamento de recursos hídricos. Para a área em estudo, as oito unidades geossistêmicas implicam na leitura dos caminhos que a água percorre, sofrendo diversas influências das características fisico-químicas oriundas das paisagens.

No que concerne aos métodos de mapeamento da paisagem, representação e análise dos dados, observa-se que o uso dos Sistemas de Informação Geográfica é imprescindível nesse tipo de trabalho, pois possibilita gerar matrizes e legendas adequadas para os Geossistemas. Dessa forma, os layouts desse método se diferenciam das representações espaciais geradas em outras abordagens, pois a complexidade de visualizar os contornos dos atributos naturais, em geral, necessita de discretização de informações.

\section{AGRADECIMENTOS}

Agradecemos ao Laboratório de Estudos Climáticos (LECLIG) da Universidade Estadual de Campinas - UNICAMP pela disponibilidade de recursos financeiros, materiais e humanos, para desenvolvimento da Tese de Doutorado do primeiro autor.

\section{REFERÊNCIAS}

ALMEIDA, A. O.; COELHO, P. A.; SANTOS, J. T. A.; FERRAZ, N. R. Crustáceos decápodos estuarinos de llhéus, Bahia, Brasil. Biota Neotropica, v. 6, p. 110-120, 2006. https://doi.org/10.1590/S1676-06032006000200024

ALVARES, C. A.; STAPE, J. L.; SENTELHAS, P. C. Köppen's climate classification map for Brazil. Meteorologische Zeitschrift, v. 22, p. 711-728, 2013. https://doi.org/10.1127/0941-2948/2013/0507

AMORIM, R. R. A representação de mapas de paisagens na escala regional: o exemplo da Região Costa do Descobrimento (Bahia). Revista da ANPEGE, v. 12, p. 245-280, 2016. https://doi.org/10.5418/RA2016.1217.0011

AMORIM, R. R.; REIS, C. H.; FERREIRA, C. Mapeamento dos geossistemas e dos sistemas antrópicos como subsídio ao estudo de áreas com riscos a inundações no baixo curso da bacia hidrográfica do rio Muriaé (Rio de Janeiro - Brasil). Territorium, v. 24, p. 89-114. 2017. https://doi.org/10.14195/1647-7723 247

AMORIM, R. R.; OLIVEIRA, R. C. As unidades de paisagem como uma categoria de análise geográfica: o exemplo do município de São Vicente-SP. Sociedade \& natureza, v. 20, p. 177-198, 2008. https://doi.org/10.1590/S1982-45132008000200011

AMORIM, R. R.; OLIVEIRA, R. C. Zoneamento ambiental, subsídio ao planejamento no uso e ocupação das terras da costa do descobrimento. Mercator, v. 12, p. $211-231,2013$.

ARAUJO, T. G.; SOUZA, M. F. L.; MELLO, W.; Z., SILVA, D. M. L. Bulk Atmospheric Deposition of Major lons and Dissolved Organic Nitrogen in the Lower Course of a Tropical River Basin, Southern Bahia, Brazil. Journal of the Brazilian Chemical Society, v. 8, p.1692-1701, 2015. 
BASTIAN, O.; GRUNEWALD, K.; SYRBE, R. U. Space and time aspects of ecosystem services, using the example of the EU Water Framework Directive. International Journal of Biodiversity Science, Ecosystem Services \& Management, v. 8, p. 5-16, 2012.

BASTIAN, O.; GRUNEWALD, K.; KHOROSHEV, A. V. The significance of geosystem and landscape concepts for the assessment of ecosystem services: exemplified in a case study in Russia. Landscape ecology, v. 30, p. 1145-1164, 2015. https://doi.org/10.1007/s10980-015-0200-x

BANDEIRA, T. V.; OLIVEIRA, I. P. A transformação na paisagem causada pela atividade mineradora na Serra da Monguba/ CE. REGNE, v. 2, nº especial, p. 1221-1230. 2016.

BERTRAND, G. Paisagem e Geografia Global. Esboço metodológico. São Paulo: Universidade de São Paulo. Instituto de Geografia. Cadernos de Ciências da Terra., v. 13, p. 1-27. 1971.

BURKHARD, B.; DE GROOT, R.; COSTANZA, R. Solutions for sustaining natural capital and ecosystem services. Ecological Indicators, v. 21, p. 1-6, 2012.

https://doi.org/10.1016/j.ecolind.2012.03.008

BURKHARD, B.; KANDZIORA, M.; HOU, Y. Ecosystem Service Potentials, Flows and Demands Concepts for Spatial Localization, Indication and Quantification. Landscape online, v. 34, p.332-240, 2014.

CAMPOS, M. C. C.; MONTANARI, R.; MARQUES JÚNIOR, J.; PEREIRA, G. T.; SOUZA, Z. M. Caracterização de Argissolos em diferentes segmentos de vertente na região de Jaboticabal, SP. Revista de Ciências Agrárias, v. 55, p. 251-259, 2012. https://doi.org/10.4322/rca.2012.072

CAVALCANTI, L. C. S. Cartografia das paisagens: fundamentos. São Paulo: Oficina de Textos. 2013

CHAUSSÊ, T. C. C.; BRANDÃO, C. S.; SILVA, L. P.; SPANGHERO, P. E. S. F.; SILVA, D. M. L. Evaluation of nutrients and major ions in streams-implications of different timescale procedures. Environmental monitoring and assessment, v. 188, p. 38, 2016.

COSTA, E. N. D.; SOUZA, J. C.; ANDRADE, M.; SOUZA, M. F. L.; SOUZA, W. F. L.; SILVA, D. M. L. Influence of hydrological pathways on dissolved organic carbon fluxes in tropical streams. Ecology and Evolution, v. 7, p. 228-239, 2017. https://doi.org/10.1002/ece3.2543

EMBRAPA, SOLOS. Sistema brasileiro de classificação de solos. Centro Nacional de Pesquisa de Solos: Rio de Janeiro, 2013.

EVANS, D. A. D.; HEAMAN, L. M.; TRINDADE, R. I. F. Baddeleyite ages from Neoproterozoic mafic dykes in Bahia, Brazil, and their paleomagnetic/paleogeographic implications Meeting of the Americas. Eos Transactions, v. 91, p. 26-40. 2010.

FRANCO, G. B.; MARQUES, E. A. G.; GOMES, R. L.; CHAGAS, C. S.; SOUZA, C. M. P.; BETIM, L. $S$. Fragilidade ambiental da bacia hidrográfica do rio Almada - Bahia. Revista de Geografia, v. 28, p. 187-205, 2011.

FIGUEIREDO A. F.; REGO, N. A. C. Risco de Salinização dos Solos da Bacia Hidrográfica do Rio Colônia - Sudeste da Bahia/Brasil. Engevista (UFF), v. 10, p. 15 - 26, 2008.

GAGARINOVA, O. V.; KOVALCHUK, O. A. Assessment of anthropogenic impacts on landscape hydrological complexes. Geography and Natural Resources, v. 31, p. 291-295, 2010. https://doi.org/10.1016/i.gnr.2010.09.016

GUADAGNIN, F.; CHEMALE, F. J.; MAGALHÃES, A.J.C. Age constraints on crystal-tuff from the Espinhaço Supergroup - Insight into the Paleoproterozoic to Mesoproterozoic intracratonic basin cycles of the Congo-São Francisco Craton. Gondwana Research, v. 27, p. 363-376, 2015. https://doi.org/10.1016/j.gr.2013.10.009

GUEDES, D. R C.; DINIZ, M. T. M. Zoneamento Geoambiental e Unidades da Paisagem: os casos dos estados de Ceará e Rio Grande do Norte. REGNE, v. 2, № Especial. p. 864-874 2016.

HARUM, T.; SACCO, P.; REGO, N. A. C.; DE PAULA, F. C. F.; DOS SANTOS, J. W. B. Modelos de vulnerabilidade hidrológica para a bacia hidrográfica do rio Cachoeira (Bahia) utilizando sistemas de informações geográficas. Gaia Scientia, v. 2, p. 89 - 95, 2008.

IBGE - Instituto Brasileiro de Geografia e Estatística (2015). Sistema IBGE de Recuperação Automática - SIDRA. Disponível em: http://www.sidra.ibge.gov. br/. Acesso em 12/06/2017.

$\begin{array}{llllll}\text { Caminhos de Geografia } & \text { Uberlândia - MG } & \text { v. 19, n. } 67 & \text { Set/2018 } & \text { p. 53-67 } & \text { Página } 65\end{array}$


KOPPEN, W. Das Geographische System der Klimate. In: KOPPEN, W. GEIGER, R. (eds.): Handbuch der Klimatologie.- Gebruder Borntrager. Berlin, p. 1-44, 1936.

LUCIO, M. Z. T.; SANTOS, S. S.; SILVA, D. M. L. Hydrohemistry of Cachoeira river (Bahia State, Brazil). Acta Limnológica Brasiliensia, v. 24, p. 181-192, 2012. https://doi.org/10.1590/S2179$\underline{\text { 975X2012005000037 }}$

MAIA, P. H. P.; CRUZ, M. J. M.; SAMPAIO, M. C. Zoneamento dos aquíferos do estado da Bahia. Brazilian Journal of Aquatic Science and Technology, v. 13, p. 45-52, 2009. https://doi.org/10.14210/bjast.v13n1.p45-52

MAGALHAES, A. J. C. SCHERER, C. M. S. RAJAGABAGLIA, G. P. Mesoproterozoic delta systems of the Açuruá Formation, Chapada Diamantina. Precambrian Research, v. 257, p. 1-21, 2015. https://doi.org/10.1016/j.precamres.2014.11.016

MELFI, A. J. Biogeochemistry of an Amazonian podzol-ferralsol soil system with white kaolin. Biogeosciences, v. 9, p. 3705-3720, 2012. https://doi.org/10.5194/bg-9-3705-2012

MUBAREKA, S. Estimation of water requirements by livestock in Europe. Ecosystem Services, v. 4, p. 139-145, 2013. https://doi.org/10.1016/i.ecoser.2013.03.001

PAULA, F. C. F.; SILVA, D. M. L.; SOUZA, C. M. Tipologias Hidroquímicas das Bacias Hidrográficas do Leste da Bahia. Revista Virtual de Química, v. 4, p. 365-373, 2012.

PEDREIRA, A. J.; WAELE, B. Contemporaneous evolution of the Palaeoproterozoic- Mesoproterozoic sedimentary basins of the São Francisco - Congo Craton. Geological Society Special Publications, v. 294 , p. $33-48,2008$. https://doi.org/10.1144/SP294.3

PEDREIRA, A. J. Sistemas Deposicionais da Chapada Diamantina Centro-Oriental, Bahia. Revista Brasileira de Geociências. São Paulo-SP, v. 27, p. 229 - 240, 1997.

PROCESSAMENTO DIGITAL. Brasil em dados. Shapeflies diversos. Disponível em: http//processamentodigital.com.br. Acesso em Junho de 2017.

REGO, N. A. C.; BARROS, S. R.; SANTOS, J. W. B. D. Avaliação espaço-temporal da concentração de coliformes termotolerantes na lagoa encantada, Ilhéus, Bahia, Brasil. REDE-Revista Eletrônica do PRODEMA, v. 4, p. 55-69, 2010.

REGO, N. A. C.; SANTOS, J. W. B.; TEIXEIRA, A. Estudos Quali-quantitativos da Condutividade Elétrica das Águas Superficiais da Bacia Hidrográfica do Ro Cachoeira-Sul da Bahia. Série Águas da Bahia, v. 3, p. 65-76, 2010.

SANTOS, J. W. B.; PAULA, F. C. F.; REGO, N. A. C. Tipologia fluvial da bacia hidrográfica do Rio Salgado, sul da Bahia. Revista Brasileira de Recursos Hídricos, v. 13, p. 217-226, 2008. https://doi.org/10.21168/rbrh.v13n1.p217-226

SEI. Superintendência de Estudos Econômicos e Sociais da Bahia. Mapas digitalizados do Estado da Bahia: base de dados. Salvador: SEI. (CD-ROM). 2004

SILVA, D. M. P.; CAMPOS, M. C. C.; ALHO, L. C.; CUNHA, J. M.; PAULA NETO, P. Variação espacial da estabilidade dos agregados e estoque de carbono em área de terra preta arqueologica sob cultivo de cacau. Revista Brasileira de Agroecologia, v. 11, p. 179-187, 2016.

SILVA, K. B. Caracterização das bacias dos Rios Colônia, Salgado e Cachoeira e suas contribuições para estudos de confluências. 2016. 86p. (Mestrado em Desenvolvimento Regional e Meio Ambiente), Universidade Estadual de Santa Cruz. Ilhéus, 2016.

SILVA, K. B.; REGO, N. A. C.; SANTOS, J. W. B. COSTA, P. A. Identification of urban heat islands as a subsidy for creation of green areas. Gaia Scientia, v. 10, p. 209-222, 2016.

https://doi.org/10.21707/gs.v10.n04a17

SILVA, V. A.; MOREAU, M. S.; MOREAU, A.M. S. S.; REGO, N.A.C. Uso da terra e perda de solo na Bacia Hidrográfica do Rio Colônia, Bahia. Revista Brasileira de Engenharia Agrícola e Ambiental, v. 15, p. 310-315, 2011. https://doi.org/10.1590/S1415-43662011000300013

SOARES, J. P. R.; AQUINO C. M. S. Systemic analysis: theoretical contribution methodology and applications in the state of Piauí, Brazil. ACTA Geográfica, v. 6, p. 239 - 255, 2012.

https://doi.org/10.5654/actageo2012.0613.0014

$\begin{array}{llllll}\text { Caminhos de Geografia } & \text { Uberlândia - MG } & \text { v. 19, n. } 67 & \text { Set/2018 } & \text { p. 53-67 } & \text { Página } 66\end{array}$


SOCHAVA, V. B. Geography and Ecology. Soviet Geography, v.12, p. 277 - 293, 1971. https://doi.org/10.1080/00385417.1971.10770247

SOCHAVA, V. B. Theoretical requisites for the mapping of the human habitat. Soviet Geography, v.16, p. 86 - 98, 1975. https://doi.org/10.1080/00385417.1975.10640055

SOCHAVA, V. B. O Estudo de Geossistemas. Métodos em questão. Tradução USP. São Paulo, 1977.

SOUZA, C. M. P.; MOREAU, M. S.; MOREAU, A. M. S.; FONTES, E. O. Níveis de Degradação de Pastagens da Bacia do Rio Colônia - BA com Uso de Imagens LANDSAT 5TM. Revista Brasileira de Geografia Física, v. 03, p. 228 - 243, 2010. https://doi.org/10.26848/rbgf.v3i3.232685

SOUZA, C. M. P.; SILVA, K. F. M. C.; Moreau, A. M. S.; FONTES, E. O.; MOREAU, M. S.; GOES, L. $M$. Zoneamento agroecológico da bacia hidrográfica do rio Colônia. Revista de Ciências

Ambientais, v. 3, p. 49-66, 2009.

SUDENE. Superintendencia de Desenvolvimento do Nordeste. Folha Camacan (SD-24-Y-D-III). Bahia, SUDENE, 1977a. Escala 1:100.000.

SUDENE. Superintendencia de Desenvolvimento do Nordeste. Folha Itabuna (SD-24-Y-B-VI). Bahia, SUDENE, 1977b. Escala 1:100.000.

SUDENE. Superintendencia de Desenvolvimento do Nordeste. Folha Ibicaraí (SD-24-Y-B-V). Bahia, SUDENE, 1977c. Escala 1:100.000.

SUDENE. Superintendencia de Desenvolvimento do Nordeste. Folha Itapetinga (SD-24-Y-D-I). Bahia, SUDENE, 1977d. Escala 1:100.000.

SUDENE. Superintendencia de Desenvolvimento do Nordeste. Folha Itaju do Colônia (SD-24-Y-DII). Bahia, SUDENE, 1977e. Escala 1:100.000.

SUDENE. Superintendencia de Desenvolvimento do Nordeste. Folha Poções (SD-24-Y-B-IV). Bahia, SUDENE, 1977f. Escala 1:100.000.

THORNTHWAITE, C.W. An approach towards a rational classification of climate. Geographical Review, v. 38, p. 55 - 94, 1948. https://doi.org/10.2307/210739

VINOGRADOV, B.V.; GERENCHUK, K.I.; ISACHENKO, A.G. Basic Principles of Landscape Mapping. Soviet Geography, v. 3, p. 15 - 20, 1962. https://doi.org/10.1080/00385417.1962.10769947

Recebido em: 27/09/2017

Aceito para publicação em: 20/03/2018 